\title{
Personality, temperament, organizational climate and organizational citizenship behavior of volunteers
}

\author{
Elżbieta Chwalibóg \\ echwalibog@gmail.com
}

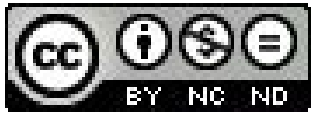

\begin{abstract}
The following article aims to present the results of studies on the relationship of temperament, personality and organizational climate with the occurrence of Organizational Citizenship Behavior (OCB) in the organization. The study was qualitative, and correlational. The study group consisted of 42 activists in voluntary organizations aged from 18 to 19 years old, 15 men and 27 women. The following questionnaires were used: The scale measuring
\end{abstract} Organizational Citizenship Behavior (OCB) S. Retowski, Formal Characteristics of Behaviour - Temperament Questionnaire (FCZ-KT) B. Zawadzki and J. Strelau, Personality Inventory NEO-PI-Costa Jr. and Mc'Crae Polish Adaptation and Organizational Climate Questionnaire by L. von Rosenstiel and R. Bögel - K. Durniat Adaptation. The study revealed a clear positive correlation with Organizational Citizenship Behavior (OCB) with a component of Agreeableness - Trust (A1), with Extraversion (E) and its components: Warmth (E1), Excitement Seeking (E5) Activity (E4) and Gregariousness (E2) and the component of Conscientiousness - Self-Discipline (C5), component of Openness to Experience - Actions (O4), and also negative correlations with Neuroticism (N) and its components: Vulnerability (N6), Self-Consciousness (N4) and Anxiety (N1). The study also revealed a clear positive correlations Organizational Citizenship Behavior (OCB) with Activity (AK), Endurance (WT) and Briskness (ŻW) and a clear negative correlation with Perseveration (PE), Emotional Reactivity (RE). In the group of volunteers there were also showed positive correlations of Organizational Citizenship Behavior (OCB) with a Career (Assessment and Promotion) (OA) and the Communication and Information (KI). Regression model developed using multiple regression (stepwise regression method) takes into account the following variables: Activity (AK - Temperament), Agreeableness component of the Personality Straightforwardness (A2), and the component of Neuroticism - Self-Consciousness (N4), also the component of Conscientiousness - Deliberation (C6) and a component of Openness to Experience - Fantasy $(\mathrm{O} 1)$ and the Organizational Climate subscale OA - Career (Assessment and Promotion). The obtained results indicate a strong relationship of personality 
and temperament variables and the organizational climate of the manifestation of Organizational Citizenship Behavior.

Keywords: Organizational Citizenship Behavior (OCB), personality, temperament, organizational climate, correlation studies, volunteers.

The topic of volunteer organizational citizenship behavior is not yet widespread in polish work psychology and organization and management studies, yet current work challenges, creativity, changing of models, schemes and procedures make it not only an asset but actually a requirement.

The specifics of voluntary work make the reasons for undertaking it neither egoistic nor financial, thus making volunteers who do it a specific group of which you can expect free will in engaging in behavior exceeding the criteria or obligations imposed by voluntary organizations. That is why it seems interesting to check the coexistence of OCB with personality features, temperament of the volunteers and the organizational climate within the institutions they work in.

\section{The concept of Organizational Citizenship Behavior}

The concept of OCB behavior (Organizational Citizenship Behavior) was first introduced by D. Organ in 1983. He defined it as "individual behavior that is discretionary, not directly or explicitly recognized by the formal reward system, and in the aggregate promotes the efficient and effective functioning of the organization. By discretionary, we mean that the behavior is not an enforceable requirement of the role or the job description, that is, the clearly specifiable terms of the person's employment contract with the organization; the behavior is rather a matter of personal choice, such that its omission is not generally understood as punishable” (Podsakoff, MacKenzie, Paine, Bachrach 2000, p. 513).

In the literature we can find different forms of organizational citizenship behavior. Metaanalisis done by P.M. Podsakoff, S.B. McKenzie, J.B. Paine and D.G. Bachrach (Podsakoff, MacKenzie, Paine, Bachrach 2000, p.518-526) covers the wider concept and distinguishes:

a. Helping Behaviors - they concern voluntary helping of others in dealing with or/ and preventing the problems connected with work. 
b. Sportsmanship - the desire $\backslash$ readiness $\backslash$ willingness to tolerate (without complaint) the inevitable inconvenience and enforcement of work and maintaining a positive attitude even when things go wrong. Not being offended when someone doesn't keep to undertakings made, and readiness to sacrifice personal desires for the good of the team. The ability not to be offended by objection or denial.

c. Organizational Loyalty - protecting the company and its goals, promoting the company, keeping up its appearance, protecting it from the external dangers, being loyal even in unfavorable conditions. Identifying with the company and its leaders, working for the common good.

d. Organizational Compliance - internalization and acceptance of rules and procedures that exist in the company, which are conscientiously and honestly abided by, even when there are no observers.

e. Individual Initiative - voluntarily going outside of own role in the organization (containing behaviors connected with the task), going out of minimal requirements or desired level of quality of the job done. These behaviors consider volunteer initiative, creativity and innovation to increase the quality of the job for the company, enthusiasm when doing one's job, making an effort to complete the task, voluntarily taking additional responsibilities and encouraging co-workers to do the same. These are all the behaviors of going outside of and beyond one's responsibilities. Organ thinks of this behaviors as being the most difficult to distinguish from behaviors connected with role or task.

f. Civic Virtue - the interest and commitment to the organization as a whole. Shows itself as willingness to actively participate in its management (e.g. attendance at the meetings, at debates concerning company's policy, showing what strategy the company should take) monitoring the environment to find threats and opportunities for the company (such as watching the growth of the competition), keeping an eye on the company's business (reporting risks, suspicious activities inside and outside the company) even when the personal costs are high. These behaviors reflect the feeling of being a part of the whole (such as a citizen feels to be a part of a country) and accepts the responsibility that comes with it.

g. Self Development includes voluntary behavior of employees concerning widening of their own knowledge, skills and abilities. 
Concerning the direction of citizenship behavior we can differentiate (after Williams and Anderson) (Podsakoff, MacKenzie, Paine, Bachrach 2000, p. 519-521):

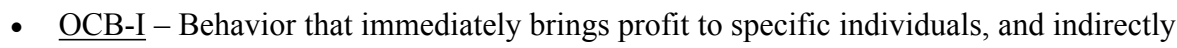
also to an organization (e.g. help after long absence or interest in other peoples' business). These behaviors fit in the category of Helping behaviors.

- $\underline{\text { OCB-O }}$ - Behavior that generally brings profit to an organization (e.g. informing about not getting to work earlier, obeying the informal rules made to keep order). These behaviors fit into the category of organizational obedience/ subordination.

Early researches in the U.S. from the 80 's focused on finding a correlation between OCB and individual characteristics of workers, their attitudes - especially the morale of the underlying job satisfaction, organizational commitment, perception of fairness, perceptions of leaders supportiveness. Correlation between these characteristics and OCB ranged from 0.23 to 0.31 (Podsakoff, MacKenzie, Paine, Bachrach 2000, p. 530), and in other studies reached even 0.44 (Organ, Podsakoff, MacKenzie 2006, p. 38-40).

Another area of research in this area were dispositions of employees, such as agreeableness, conscientiousness, positive and negative emotionality. Studies have shown a positive relationship, although weak, between these dispositions and OCB. Correlations were from 0.04 to 0.30 (highest for conscientiousness). Predispositions to show OCB are: empathy, need for achievement, affiliation need, pro-active attitude, loyalty, planning. The general trend of research shows that the relationship between personality and OCB are weak, perhaps this relationship is not direct and attitude can mediate (Organ, Podsakoff, MacKenzie 2006, p. 45-49).

Perception of the role - the ambiguity or conflict of roles - the majority of studies showed a weak negative relationship with OCB (correlations from -0.02 to -0.16 ). These two phenomena are linked with job satisfaction and satisfaction is correlated with the OCB, which is why it appears to be a mediator of that relationship. Demographic variables, like seniority in the organization and gender of the workers are not correlated with OCB (Podsakoff, MacKenzie, Paine, Bachrach 2000, p. 530-531).

The characteristics of the tasks show significant, but low correlations with OCB. Of areas that have been studied primarily feedback, automated/ routinization of the work, satisfaction that comes with the job. Feedback (from 0.16 to 0.21 ) and job satisfaction (from 0.14 to 0.27 ) are positively correlated with $\mathrm{OCB}$, whereas a negative routinization (from -0.10 to -0.30) (Podsakoff, MacKenzie, Paine, Bachrach 2000, p. 531-532). 
Research shows that formalization, inflexibility of the organization, support counselors, distance in space are not correlated with OCB. Compounds that have been discovered, relate to the consistency group (from 0.12 to 0.20 ), perceived support of the organization (0.31) and rewards beyond the control of the leader (from -0.03 to -0.17) - the first two proved to be positive and the third negative (Podsakoff, MacKenzie, Paine, Bachrach 2000, p. 532).

In this area, more research was conducted and a number of relationships discovered with OCB. Transformational leadership behavior, developing a vision, providing an appropriate model, building acceptance for group goals, expectations for a high level of performance, and intellectual stimulation are positively correlated with OCB, oscillating at around 0.2. A positive correlation was also found between reward of leader behavior, and a negative one with punishment. Subsequent studies have been shown that support leadership behavior and clearly outlined the role of a leader as also positively correlated with OCB. The general behavior for the exchange of leader - member organization correlate with OCB at 0.3 (Podsakoff, MacKenzie, Paine, Bachrach 2000, p. 518-533). There is suspicion that some of the leadership behavior correlates with OCB through the influence of employee attitudes (e.g., sense of justice).

\section{Description of conducted research}

The research covered a group of 42 activist involuntary organizations country-wide working in Wrocław, comprising mainly students. The group consisted of people aged 18 to 49, 15 men and 27 women. Subjects had mainly secondary education (general and vocational) or higher education degree (licentiate) which can be explained by the fact that it is mostly a group of students still in the course of education.

Each person received a printed questionnaire. The research was anonymous. The research was conducted during 4 months (September 2008 - December 2008). Each participant filled in the questionnaire at a time and place suitable for him/ herself.

The research used the following tools:

a. OCB Scale by S. Retowski - this scale consists of 32 sentences (18 sentences concern OCB-O and 14 sentences $=$ OCB-I). Reliability for OCB-O positions measured by $\alpha$ Cronbach was 0.80 for OCB-I positions 0.77 (Retowski, Bogdanowicz, Dolata, Kaźmierczak, 2003, p.190).

b. The Formal Characteristics of Behavior - Temperament Inventory (FCB-TI) developed by J. Strelau and B. Zawadzki to diagnose the temperament with 120 
positions - 20 for each of 6 scales: Briskness, Perseveration, Sensory Sensitivity, Emotional Reactivity, Endurance and Activity. Reliability measured by $\alpha$-Cronbach was from 0.73 dor Sensory Sensivity to 0.85 for Endurance (Strelau, 2003, p.125126).

c. NEO-PI-R Personality Inventory by P.T. Costa Jr and R.R. McCrae Polish Adaptation - is a tool used for diagnose the personality characteristic in a five factor models (The Big Five). The inventory consists of 240 statements -48 for each of the five factors: Neuroticism, Extraversion, Openness, Agreeableness and Conscientiousness. Every factor consists of 6 components. Reliability measured by internal compatibility (with $\alpha$-Cronbach) was sufficiently high: the lowest value has Agreeableness scale (alfa $=0.81$ ), for others scales coefficients were very similar (range from 0.85 to 0.86 ) (Siuta 2006, p.25-37).

d. Organizational Climate Questionnaire by L. von Rosenstiel and R. Bögel Adaptation K. Durniat - this German tool is used to investigate organizational climate, it was imported to Poland by S.A. Witkowski, and Z. Zaleski, now in its revised form validated and adapted to Polish conditions by K. Durniat. There are six dimensions in assessing the climate of the organization: The relationship between employees, supervisors directing style, organization of work in the company, Information and communication in the company, representing the interests of the employee, creating opportunities for staff development (promotions, evaluations, motivation). Reliability of the subscales ranges from 0.81-0.92 (Durniat, 2008, p. 120-144, 298-317).

In the study with the absence of a clear theoretical base, difficulties in defining the concept of Organizational Citizenship Behavior and in the designation of its clear limits, and no similar studies in Poland formulates the following research questions:

1. Is there a link between personality traits according to the Five-scale Theory of Personality and Organizational Citizenship Behavior?

2. Is there a link between temperamental traits according to the Regulatory Theory of Temperament and Organizational Citizenship Behavior?

3. Is there a relationship between dimensions of organizational climate by the L. von Rosenstiel and Bögel's Concept of Organizational Climate and Organizational Citizenship Behavior? 


\section{Test results}

The studies did not reveal a significant relationship between demographic variables and Organizational Citizenship Behavior. Correlations of Organizational Citizenship Behavior with gender, age, education, experience and overall experience in the current organization is too small and not statistically significant enough to be the basis for inference. Table 1. presented significant correlations at $\mathrm{p}<0.05$ in the group of volunteers:

Table 1. Correlations (Pearson's coefficient) significant at the level of significance equal to $p<0.05$ between the behaviors and variables Organizational Citizenship Behavior personality, temperament and climate-related organization in a group of volunteers $(n=42)$

\begin{tabular}{|c|c|}
\hline Variable correlated significantly & $\begin{array}{l}\text { The level of correlation } \\
\text { (Pearson correlation coefficient) }\end{array}$ \\
\hline A1-Trust & 0.42 \\
\hline E1 - Warmth & 0.41 \\
\hline E5 - Excitement-Seeking & 0.39 \\
\hline E-Extraversion & 0.38 \\
\hline C5 - Self-Discipline & 0.34 \\
\hline O4 - Actions & 0.33 \\
\hline E4 - Activity & 0.33 \\
\hline E2 - Gregariousness & 0.31 \\
\hline N6 - Vulnerability & -0.35 \\
\hline N4 - Self-Consciousness & -0.37 \\
\hline $\mathrm{N}$ - Neuroticism & -0.42 \\
\hline N1 - Anxiety & -0.48 \\
\hline AK - Activity & 0.63 \\
\hline WT - Endurance & 0.32 \\
\hline ŻW - Briskness & 0.32 \\
\hline PE - Perseveration & -0.35 \\
\hline RE - Emotional Reactivity & -0.56 \\
\hline OA - Career (Assessment and Promotion) & 0.42 \\
\hline KI - Communication and Information & 0.40 \\
\hline
\end{tabular}

Source: Author

The study revealed a clear positive correlation between Organizational Citizenship Behavior (OCB) with a component of Agreeableness - Trust (A1), with Extraversion (E) and its components: Warmth (E1), Excitement Seeking (E5) Activity (E4) and Gregariousness (E2) and the component of Conscientiousness - Self-Discipline (C5), component of Openness 
to Experience - Actions (O4), and also negative correlations with Neuroticism $(\mathrm{N})$ and its components: Vulnerability (N6), Self-Consciousness (N4) and Anxiety (N1). A clear positive correlations also appear in Organizational Citizenship Behavior (OCB) with Activity (AK), Endurarance (WT) and Briskness ( $\mathrm{Z} W)$ and a clear negative correlation with Perseveration (PE), Emotional Reactivity (RE). In the group of volunteers there were also showed positive correlations of Organizational Citizenship Behavior (OCB) with a Career (Assessment and Promotion) (OA) and the Communication and Information (KI).

To create a model describing the variable Organizational Citizenship Behavior that using other variables there has been used a multiple regression, using the method of stepwise regression. In the group of volunteers to the regression model variables were selected as follows: Activity (AK - Temperament), Agreeableness component of the Personality Straightforwardness (A2), and the component of Neuroticism - Self-Consciousness (N4), also the component of Conscientiousness - Deliberation (C6) and a component of Openness to Experience - Fantasy (O1) and the Organizational Climate subscale OA - Career (Assessment and Promotion). The created model can explain 65\% of the variability of the variable OCB. We can reject the hypothesis of no linear relationship between variables in the model and the explained variable OCB.

The research questions received a positive response in the described studies.

\section{Discussion of results}

Groups of volunteers are young, still learning. A regression model would characterize the Organizational Citizenship Behavior of the VOLUNTEER as a person who is:

a. active (AK), willingly and easily, to undertake a task of high stimulation.

b. open, and has honest relationships with others (A2). Perhaps more socially oriented persons exhibit Organizational Citizenship Behavior pro-worker OCB-Idirected at others. With sensitivity to others the volunteer helps solve problems, grants him/ her self, cooperates. Such personality traits give some guidance on the motivations to display Organizational Citizenship Behavior. The resulting picture shows that they are social-oriented people and perhaps all the motives associated with interpersonal relations - establishing relationships, maintaining and deepening them - makes volunteers more likely to undertake such Organizational Citizenship Behavior.

c. not afraid of problematic social situations that may cause embarrassment, shame (N4). Thanks to that the volunteer does not fear that he/ she will not be able to help 
or his/her action appears to be unnecessary - this self-confidence in social contacts may be related to the manifestation of Organizational Citizenship Behavior that cannot be regarded as beneficial in every environment.

d. spontaneous decision-making, regardless of consequences (C6). Volunteer being a young person goes beyond the agreed standards of behavior by revealing its spontaneity and activity, so they take decisions faster and go straight into action.

e. focused on what he now occupies, on a particular issue or situation (O1). It seems that the volunteer responds to a specific emerging issue, idea or concept, which can often take Organizational Citizenship Behavior with this issue.

f. working within an organization, in which reward and motivation has a variety of forms. Such organization offers the potential for fulfillment, reward and promotion. Here we clearly see the volunteer expectation of career development. There is also the question of whether the prospect of promotion, doesn't cover the pro-social character of Organizational Citizenship Behavior.

Correlations obtained in the studies highlight the importance of other characteristics are manifested in VOLUNTEERS Organizational Citizenship Behavior such as:

a. Low Neuroticism (N) - a person emotionally stable, suitable, sustainable, selfsatisfied, feeling safe and in dealing in stressful situations.

b. Low Anxiety (N1) - calm, relaxed person who does not risk upset on matters likely to end badly.

c. Low Self-Consciousness (N6) - the person is not afraid of social situations, that are likely to cause shame or embarrassment.

d. Low Vulnerability (N6) - is able to cope with difficult situations.

e. High Extraversion (E), and Warmth (E1), Gregariousness (E2), Activity (E4), Excitement-Seeking (E5) - socialized person, involved in interpersonal contacts, energetic, emotional, people-friendly, easily falling into close relationships, sincerely fond of others, happy staying with others, thus seeking stimulation. This feature allows the personality of volunteers to think about the motivation of manifesting Organizational Citizenship Behavior. The resulting picture shows that they are socially oriented people and motivations for interpersonal relations may be important here.

f. High Actions (O4) - undertaking various activities, preferring changeability, and new information. 
g. High Self-Discipline (C5) - motivated to complete ongoing tasks.

h. High Trust (A1) - a person who believes that others are honest and have good intentions.

i. High Briskness ( $\dot{Z} \mathrm{~W})$ - respond quickly, has a high rate of activity.

j. High Endurance (WT) - adequately respond to the strong and long-term stimulation.

k. Low Emotional Reactivity (RE) and Perseveration (PE) - reacts calmly, possesses emotional resilience, and does not repeat the behavior, along with the disappearance of stimulus stops the behavior.

1. Communication and Information (KI) in the organization are of high quality, clear wording, bilateral movement, receiving and possession of information motivates the volunteer.

In our study the correlation between the Big Five and Organizational Citizenship Behavior are much higher than in the U.S. studies. There appear to be a lot more correlations and they are stronger. There we can see a clearer link between Extraversion and Organizational Citizenship Behavior than between Conscientiousness with Organizational Citizenship Behavior. However, only further research and verification of the obtained results will determine whether the characteristics in such a great degree will effect on the manifestation of the Organizational Citizenship Behavior.

There was also obtained a clear correlation between temperament and Organizational Citizenship Behavior. This element has not yet been tested in Poland, it showed the link between temperamental variables, particularly Activity, Lively and Emotional Reactivity with Organizational Citizenship Behavior.

The obtained results revealed no significant correlation between the presence of the Organizational Citizenship Behavior and gender, education or work experience. This may result from the deliberate selection of the group and the uneven distinction in these variables.

Deeper analysis of the obtained results, raises further questions about the motivation of particular persons in connection with the Organizational Citizenship Behavior. Lack of coherent theory ground makes it more difficult to interpret the results. especially in the definitional range - does the prospect of career path in the company or awards delayed in time exclude naming this behavior a Organizational Citizenship Behavior. Perhaps the issues of motivation are not important here, if Organizational Citizenship Behavior are treated as going beyond the requirements of the position non-awarding in a direct way - in this case, every 
motivation, even a selfish one can be called Organizational Citizenship Behavior. Similarly, the issue of the research tool - whether declared manifestation of Organizational Citizenship Behavior can be used as an indicator. From the perspective of studies it seems to me that this is not a great method of measurement. The question arises whether such a large departure from the general level to the more detailed tools, for example, created for the specific job and tasks appearing in such work would better capture the manifestation of Organizational Citizenship Behavior - it seems hard to compare types of Organizational Citizenship Behavior revealing for example, in the manager's work with those displayed by an employee of the production or customer service.

\section{Summary}

The obtained results confirmed the link between Organizational Citizenship Behavior with personality and temperament, of volunteers and the organizational climate of the institution in which they operate. They are also a review of the results appearing in the foreign studies in Poland. Organizational Citizenship Behavior is a concept that has yet to be refined both the theoretically and empirically, but the importance of the issues it describes makes us want look at them carefully and review them in further studies.

Organizational Citizenship Behavior seems to be beneficial for the organization - the staff member who goes beyond his responsibilities both at co-worker and organization level contributes to better functioning in each of these areas. Organizational Citizenship Behavior is by its nature pro-social and if we do not encroach on the complex issues of motivation of such behavior, it appears that it will usually manifest itself when the employee and the organization are "well matched". Therefore, it seems to be a key strength of the correlations obtained. This may provide an important indication for employers seeking volunteers. If it is relevant for the work to manifest the Organizational Citizenship Behavior, we should take into account the variables of personality and temperament for recruitment, or on the other hand to create a climate of an organization that may affect such behavior.

\section{Bibliography}

Durniat K. (2008), Społeczno-organizacyjne uwarunkowania mobbingu, Unpublished Doctoral Thesis under prof. dr hab. S. A. Witkowskiego guidance, University of Wroclaw, Faculty of Historical and Pedagogical Sciences, Psychology Institute, Wrocław.

Organ D.W., Podsakoff P.M., and MacKenzie S.B. (2006), Organizational Citizenship Behavior: Its Nature, Antecedents, and Consequences, Sage Publications, Thousand Oaks. 
Podsakoff P.M., MacKenzie S.B., Paine J.B., Bachrach D.G. (2000), Organizational Citizenship Behaviors: A Critical Review of the Theoretical and Empirical Literature and Suggestions for Future Research, "Journal of Management" 26/3.

Retowski S. Bogdanowicz A., Dolata J., Kaźmierczak M. (2003), Przywiazanie organizacyjne i percepcja sprawiedliwości organizacyjnej jako predykatory zachowań w organizacji, [in:] Witkowski S. A. (ed.), Psychologiczne wyznaczniki sukcesu w zarzqdzaniu, Vol. VI, Wydawnictwo Uniwersytetu Wrocławskiego, Wrocław.

Siuta J. (2006), Inwentarz Osobowości NEO-PI-R Paula T. Costy Jr i Roberta R. McCrae. Adaptacja polska. Podręcznik, Pracownia Testów Psychologicznych, Warszawa.

Strelau J. (2006), Temperament jako regulator zachowania z perspektywy pótwiecza badań. Gdańskie Wydawnictwo Psychologiczne, Gdańsk. 